\title{
APLIKASI SISTEM PENERIMAAN PESERTA DIDIK BARU PADA SEKOLAH DASAR NEGERI NAGRAK 01
}

\author{
Agung Prastiwa Hadi Samudra ${ }^{1}$, Yulianingsih ${ }^{2}$, Pandhu Pramarta ${ }^{3}$ \\ Program Studi Teknik Informatika, Fakultas Teknik dan Ilmu Komputer, \\ Universitas Indraprasta PGRI \\ Jalan Raya Tengah No 80, Kelurahan Gedong, Pasar Rebo, Jakarta Timur \\ agungphs29@gmail.com¹, yuliaunindra@gmail.com², pandhu.unindra@gmail.com³
}

\begin{abstract}
Abstrak
Pada zaman modern seperti saat ini dengan kemajuan teknologi yang sangat pesat, kita membutuhkan sumber daya manusia yang berkualitas baik. Untuk itu, sekolah sebagai salah satu sarana pendidikan formal harus dapat memberikan pelayanan atau fasilitas yang terbaik untuk siswa-siswanya dan juga kepada orang tua/wali siswa. Penelitian ini bertujuan untuk memudahkan proses pengelolaan data dan laporan agar lebih akurat dan terstruktur lebih baik menggunakan sistem komputerisasi, dimana sistem yang dirancang sudah terintegrasi dalam suatu database. Metode penelitian yang digunakan adalah metode Research and development sebagai metode penelitian yang secara sistematis bertujuan untuk mencari atau menemukan prosedur tertentu yang lebih unggul, baru, efektif, efisien, produktif, dan bermakna. Dengan dirancangnya Aplikasi Sistem Penerimaan Penerimaan Peserta Didik Baru Pada SD Negeri Nagrak 01 dapat diharapkan membantu bagian admin dalam proses pendaftaran dan memudahkan admin dalam pembuatan laporannya.
\end{abstract}

Kata Kunci: Aplikasi, Sistem, Penerimaan Siswa Baru

\begin{abstract}
In modern times like today with very rapid technological advances, we need good quality human resources. For this reason, the school as one of the means of formal education must be able to provide the best service or facilities for its students and also to parents / guardians of students. This research aims to facilitate the process of managing data and reports to be more accurate and better structured using computerized systems, where the designed system is already integrated in a database. Research and development methods are research methods that systematically aim to find or find certain procedures that are superior, new, effective, efficient, productive, and meaningful. With the design of the Application of The New Student Admission System at Nagrak State Elementary School 01 can be expected to help the admin part in the registration process and facilitate admins in making their reports.
\end{abstract}

Keyword: Applications, Systems, New Student Admissions

\section{PENDAHULUAN}

SD Negeri Nagrak 01 merupakan sekolah Dasar yang ada di Kabupaten Bogor. Sekolah ini memiliki sistem layanan yang masih menggunakan secara manual. kemajuan teknologi yang sangat pesat, kita membutuhkan sumber daya manusia yang berkualitas baik. Untuk itu, sekolah sebagai salah satu sarana pendidikan formal harus dapat memberikan pelayanan atau fasilitas yang terbaik untuk siswasiswanya dan juga kepada orang tua/wali siswa. Layanan bagi siswa, sekolah harus memberikan layanan kemudahan mendapatkan informasi tentang penerimaan siswa baru secara cepat, tepat, dan akurat. Sehingga semakin cepat proses penerimaan siswa baru yang telah diterapkan untuk segera diperbaharui agar penerimaan siswa baru di sekolah sanggup bersaing dengan sekolah lain. Dengan adanya aplikasi sistem penerimaan peserta didik baru yang diterapkan pada SD Negeri Nagrak 01, diharapkan dapat mengatasi permasalahan yang dihadapi dan memudahkan pihak sekolah untuk meningkatkan layanan.

\section{PENELITIAN RELEVAN}

Penelitian relevan merupakan penelitian terdahulu atau sebelumnya yang relevan dengan konsep penelitian sehingga menjadi acuan atau dasar mengembangkan suatu hasil penelitian sebelumnya. 
Berikut peneliti mengambil sumber dari jurnal (Putri, 2014) yang berjudul Perancangan Sistem Informasi Penerimaan Siswa Baru Pada Sekolah Menengah Kejuruan Negeri 3 Pacitan, pada laporan SMK 3 pacitan belum terdapat laporan pembayaran. Untuk lebih menyempurnakan hasil yang didapat, maka peneliti perlu menambahkan laporan pembayaran.

Dalam penelitian selanjutnya yang pernah dilakukan oleh (Endang Kuswati, 2013) dengan judul Pembangunan Sistem Informasi Penerimaan Siswa Baru Sekolah Menengah Kejuruan ( SMKN ) 2 Donorjo Pacitan dalam Upaya Meningkatkan Pelayanan SMKN 2 Donorjo Pacitan terdapat 3 laporan, yaitu laporan Pendaftaran, laporan data kelulusan, laporan pembayaran. Untuk memudahkan SMKN 2 Donorjo Pacitan merekapitulasi data Siswa, maka peneliti perlu menambahkan laporan data Siswa.

Penelitian selanjutnya adalah (Susana Eviani, Syafrika Deni Rizki, 2016) yang berjudul Sistem Informasi Penerimaan Siswa Baru Berbasis Web Pada SMPN 34 Kabupaten Tebo, pada entity relationship diagram terdapat 2 laporan, yaitu laporan data pendaftaran dan laporan hasil seleksi, belum terdapat laporan registrasi dan laporan pembayaran . Untuk lebih menyempurnakan hasil yang didapat, maka peneliti perlu menambahkan laporan registrasi dan laporan pembayaran sebagai bukti registrasi ulang dan proses pembayaran pada Tata Usaha.

\section{METODE PENELITIAN}

\section{Desain Penelitian}

Dalam penelitian ini, digunakan metode penelitian research and development. "Research and development merupakan metode penelitian yang secara sengaja, sistematis, bertujuan/diarahkan untuk mencari atau menemukan, merumuskan, memperbaiki, mengembangkan, menghasilkan, menguji keefektifan produk, metode/strategi/cara, jasa, prosedur tertentu yang lebih unggul, baru, efektif, efisien, produktif, dan bermakna". (Putra, 2011)

\section{Teknik Pengumpulan Data}

1. Observasi

Observasi dilakukan dengan survey ke lokasi untuk mendapatkan informasi dasar yang dibutuhkan terhadap objek yang diteliti. Penelitian ini dimulai dengan permintaan izin untuk melakukan penelitian kepada Kepala Sekolah SD Negeri Nagrak 01 guna melengkapi kebutuhan Aplikasi Sistem Penerimaan peserta didik baru pada SD Negeri Nagrak 01.

2. Wawancara

Sehubung dengan adanya pandemi COVID-19, teknik wawancara dengan karyawan yang bertugas deilakukan secara online dengan memanfaatkan media social ZOOM. Teknik wawancara yang digunakan dalam penelitian ini adalah menggunakan teknik wawancara yang terstruktur. Maksudnya adalah proses wawancara dilakukan secara terencana, dalam hal ini peneliti terlebih dahulu menyiapkan interview guide sebagai panduan dalam mewawancarai informan untuk mendapatkan informasi.

\section{HASIL DAN PEMBAHASAN \\ Diagram Konteks}

"Diagram konteks menggambarkan sumber serta tujuan data yang akan diproses atau dengan kata lain diagram tersebut digunakan untuk menggambarkan sistem secara umum atau global dari keseluruhan sistem yang ada”. (Ramadhani, 2011) 
Berikut adalah Diagram Konteks yang dibuat untuk aplikasi ini:

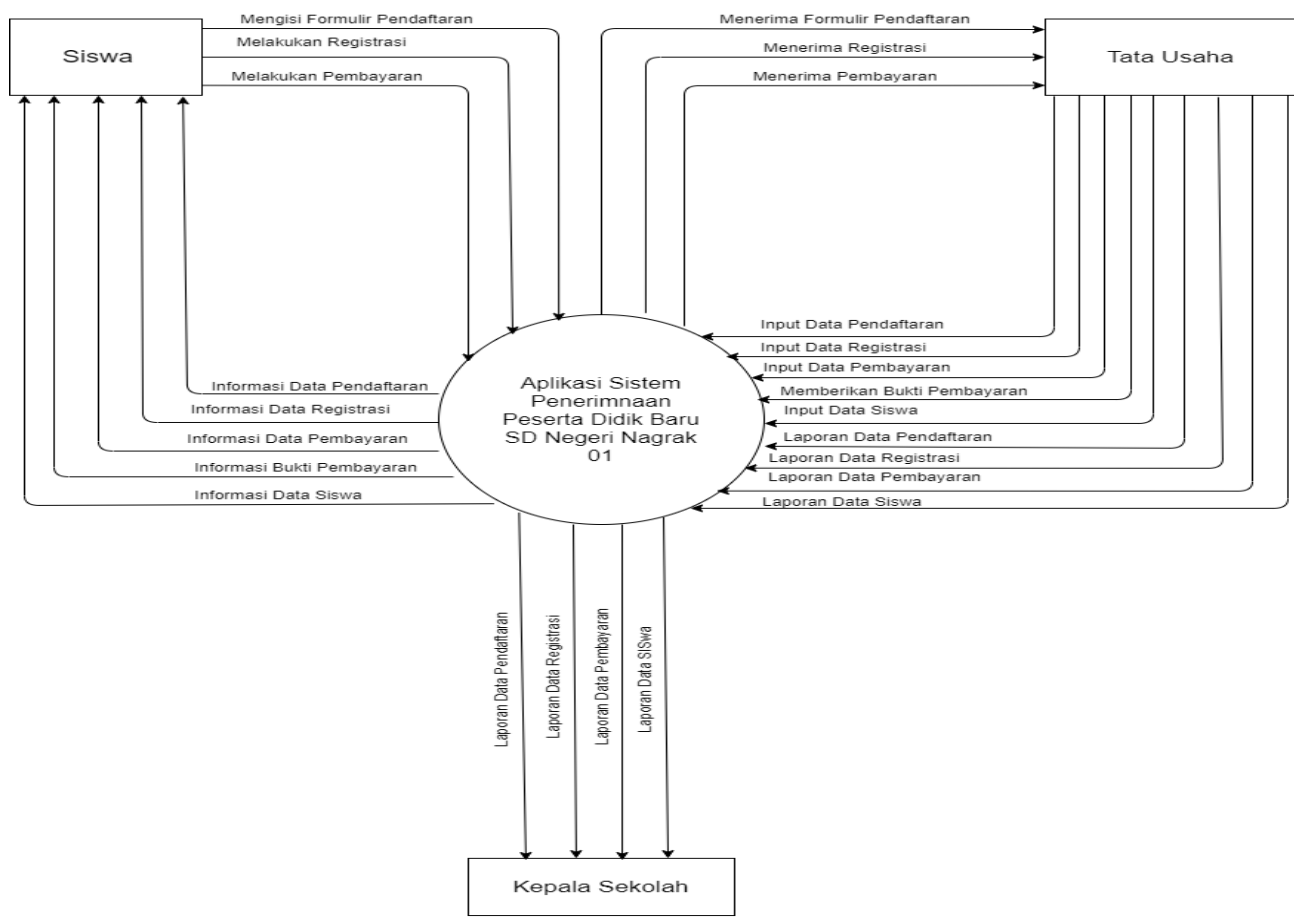

Gambar 1. Diagram Konteks Sistem yang Diusulkan

\section{Entity Relationship Diagram (ERD)}

Entity Relationship Diagram (ERD) adalah alat pemodelan data utama dan akan membantu mengorganisasi data dalam suatu proyek ke dalam entitas-entitas dan menentukan hubungan antarentitas.

Berikut adalah ERD yang dibuat untuk aplikasi ini:

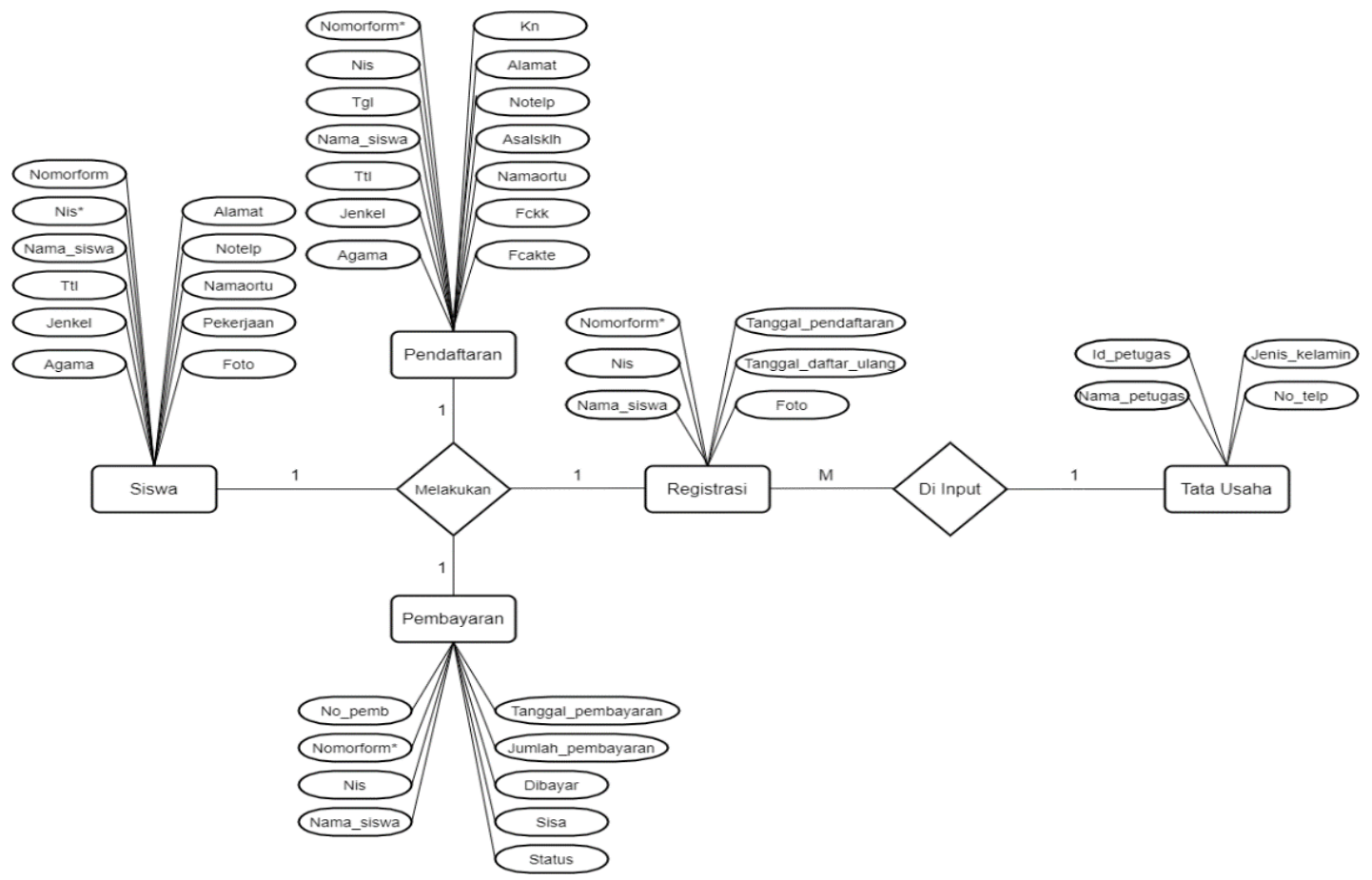

Gambar 2. Entity Relationship Diagram (ERD) 


\section{Tampilan Layar Sistem}

1. Tampilan Layar Login

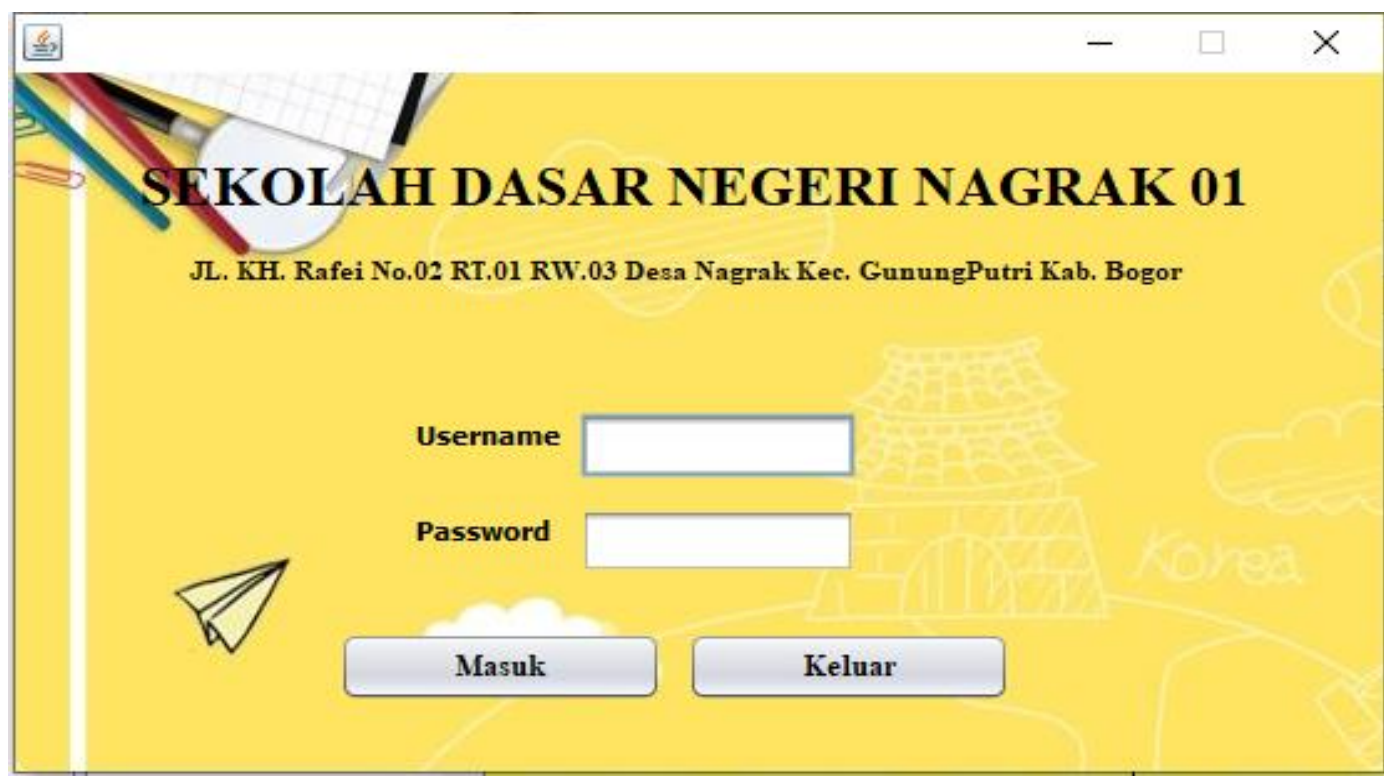

Gambar 3. Tampilan Layar Login

Tampilan di atas merupakan rancangan tampilan Login. Tampilan login menampilkan username dan password. Tombol login digunakan ketika username dan pasword sudah terisi dengan benar. Ketika pengguna sudah mengisi username dan pasword dengan benar akan menampilkan menu utama pada program tersebut. Sedangkan tombol menu keluar untuk menutup program yang sedang digunakan.

2. Tampilan Layar Menu Utama

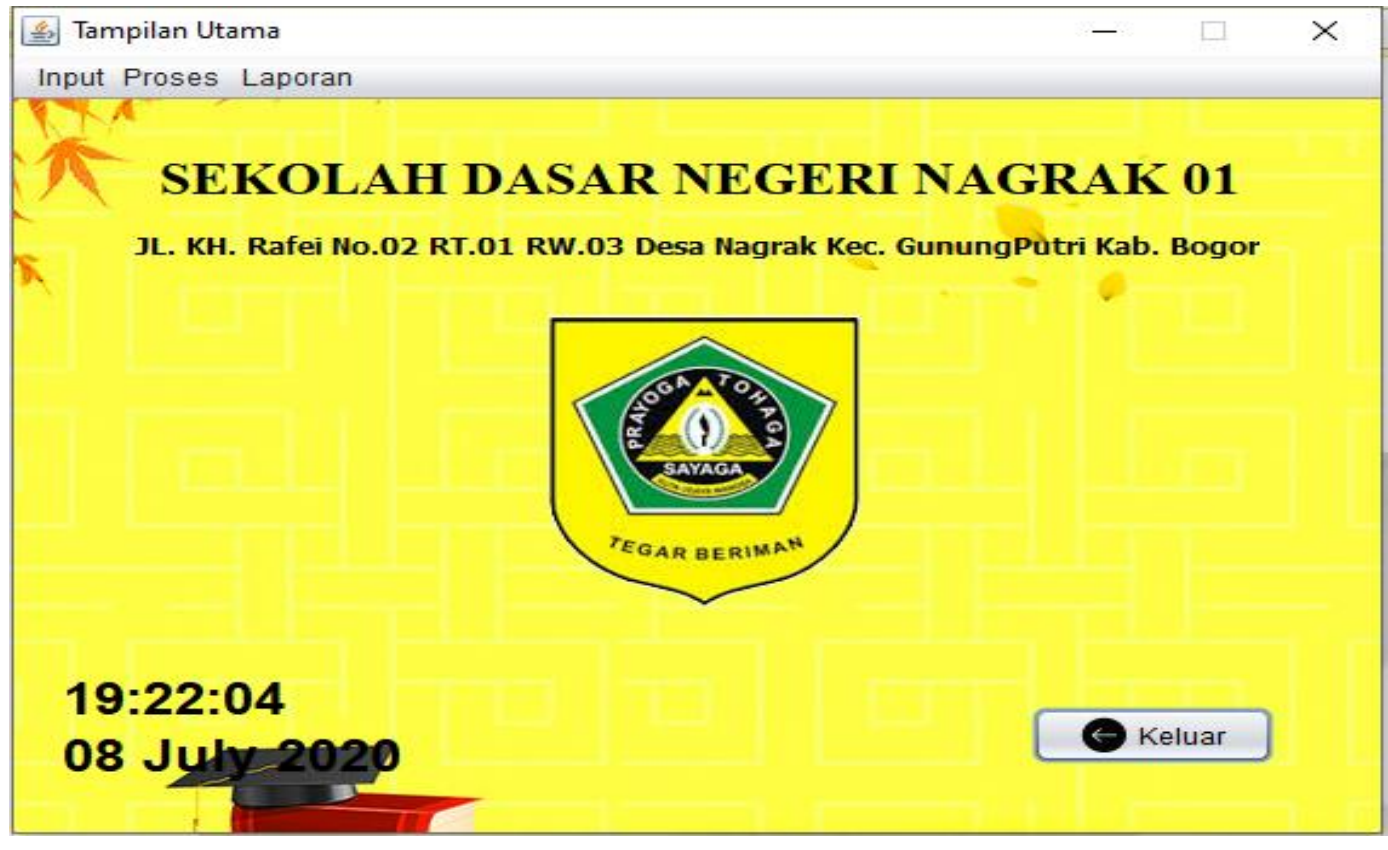

Gambar 4. Tampilan Layar Menu Utama

Pada tampilan layar form masukan menu utama, terdapat beberapa menu bar yang terdiri dari Input, Proses dan Laporan. 
3. Tampilan Layar Pendaftaran

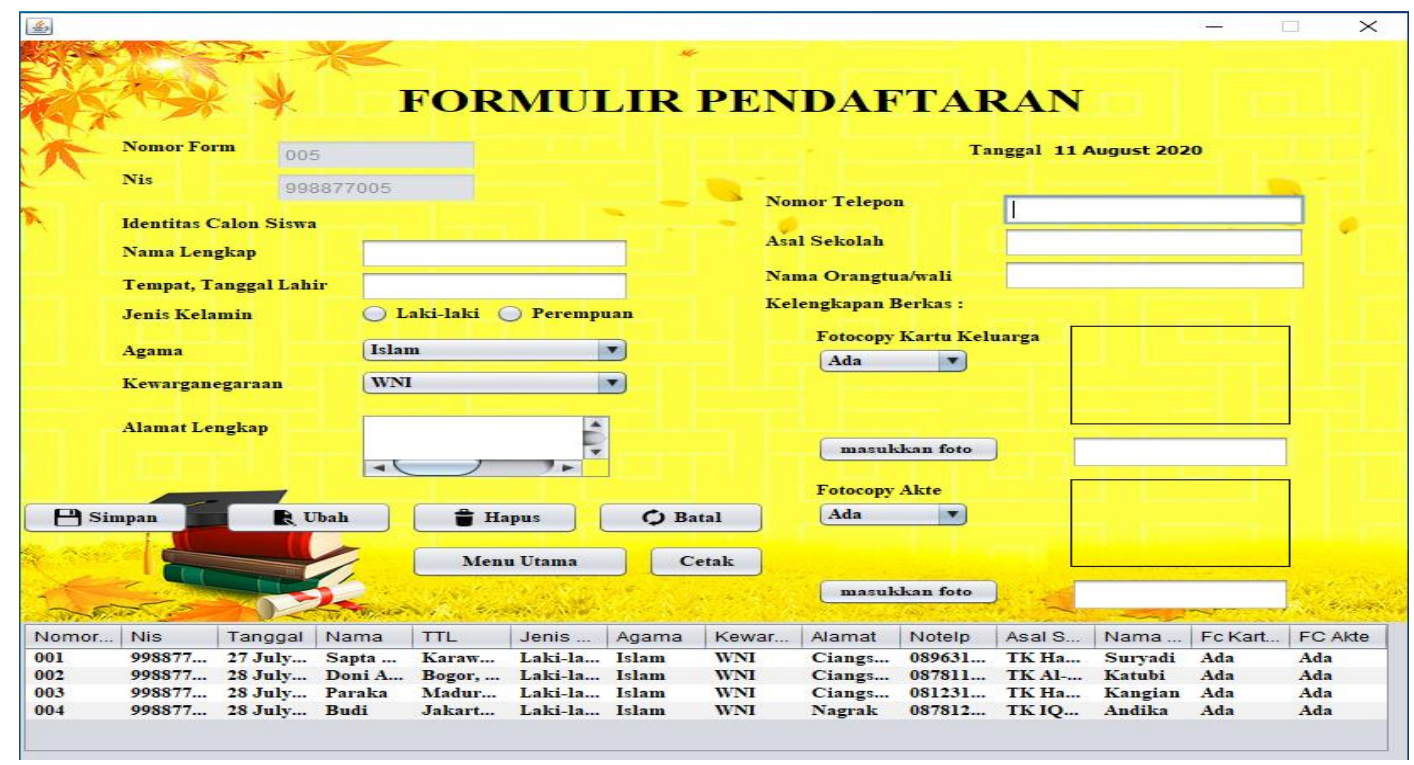

Gambar 5. Tampilan Layar Menu Pendaftaran

Tampilan di atas merupakan rancangan tampilan form Pendaftaran. Tampilan tersebut diisi ketika siswa melakukan pendaftaran dan di dalam tampilan form pendaftaran terdapat empat tombol yaitu tombol simpan digunakan untuk menyimpan data siswa yang melakukan pendaftaran, tombol ubah untuk mengubah data siswa, tombol hapus untuk menghapus data siswa yang telah mendaftar, tombol batal untuk membatalkan data siswa, tombol menu utama digunakan untuk kembali pada layar menu utama.

4. Tampilan Layar Registrasi

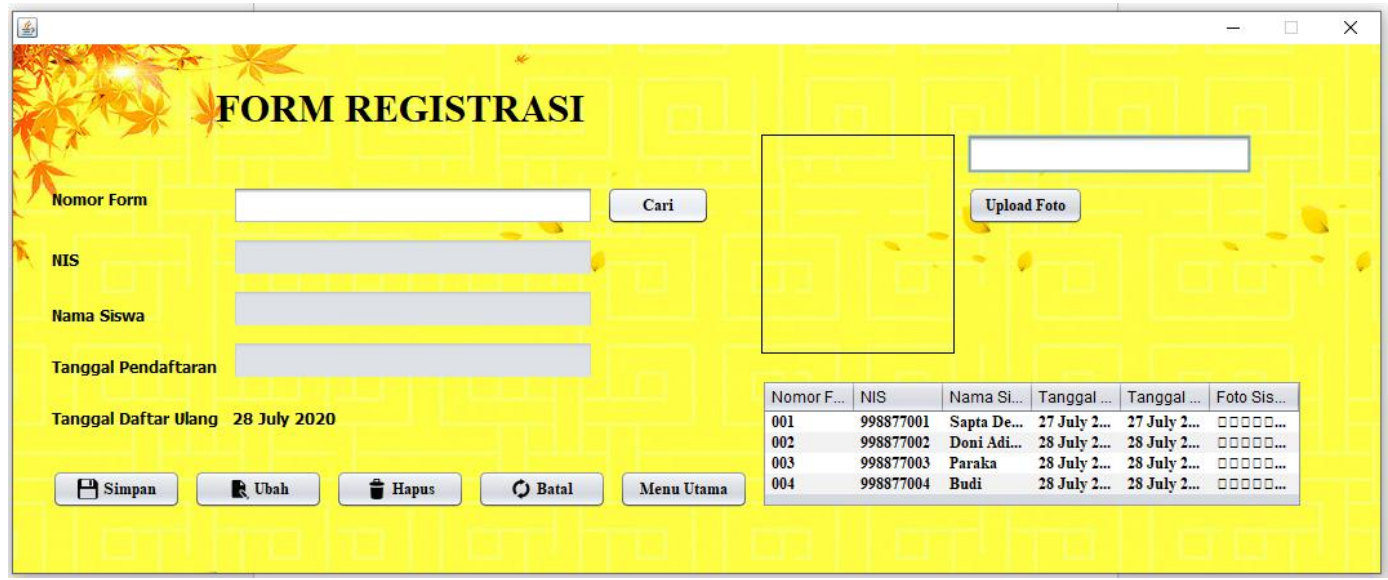

Gambar 6. Tampilan Layar Menu Registrasi

Tampilan di atas merupakan rancangan tampilan form Registrasi. Tampilan tersebut diisi ketika siswa telah melakukan seleksi offline dan sudah menerima nilai ujian dan melakukan daftar ulang, di dalam tampilan form registrasi terdapat empat tombol yaitu tombol simpan digunakan untuk menyimpan data siswa yang mengisi form registrasi, tombol ubah untuk mengubah data siswa, tombol hapus untuk menghapus data siswa yang telah mengisi form registrasi, tombol batal untuk membatalkan data siswa, tombol menu utama digunakan untuk kembali pada layar menu utama. 
5. Tampilan Layar Pembayaran

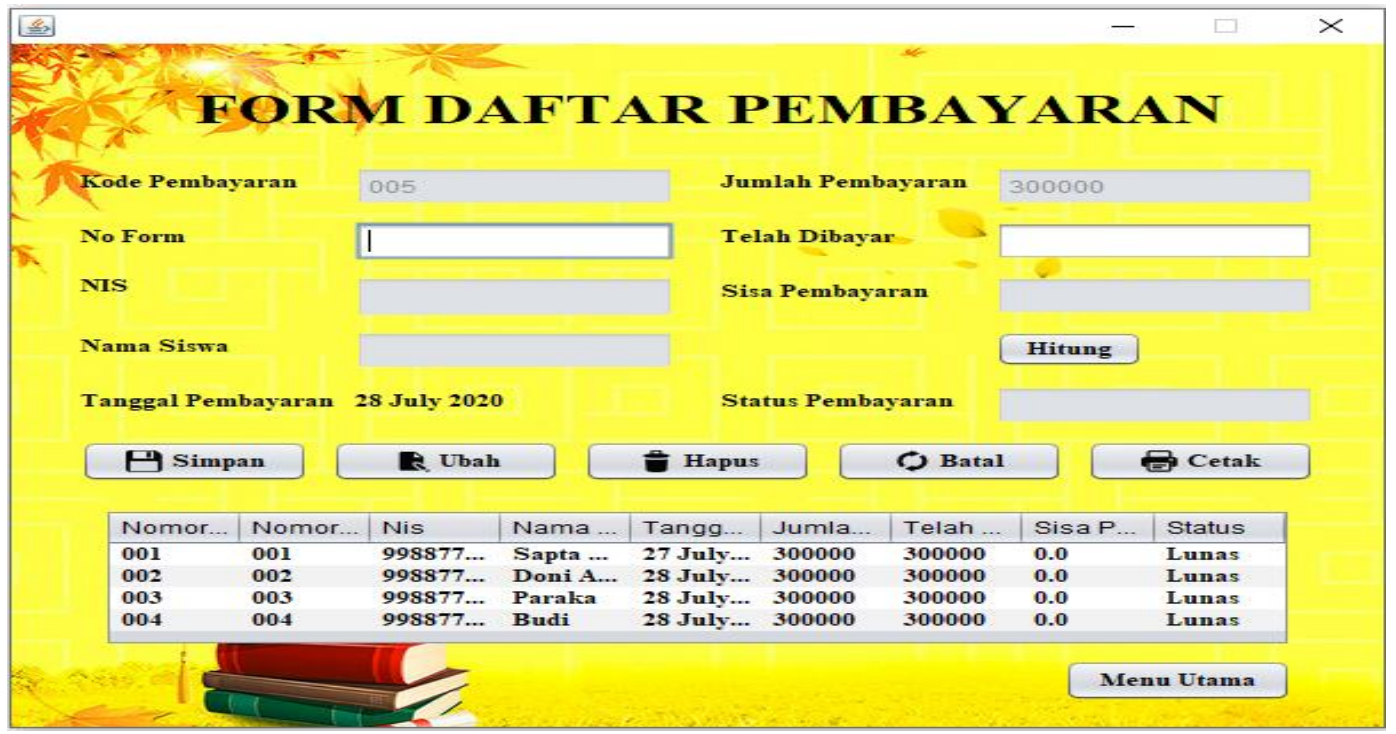

Gambar 7. Tampilan Layar Menu Pembayaran

Tampilan di atas merupakan rancangan tampilan form Pembayaran. Tampilan tersebut diisi ketika siswa telah diterima dan langsung mengisi form pembayaran di dalam tampilan form pembayaran terdapat empat tombol yaitu tombol simpan digunakan untuk menyimpan data siswa yang mengisi form pembayaran, tombol ubah untuk mengubah data siswa yang mengisi form pembayaran, tombol hapus untuk menghapus data siswa yang telah mengisi form pembayaran, tombol batal untuk membatalkan data siswa, tombol menu utama digunakan untuk kembali pada layar menu utama.

6. Tampilan Layar Data Siswa

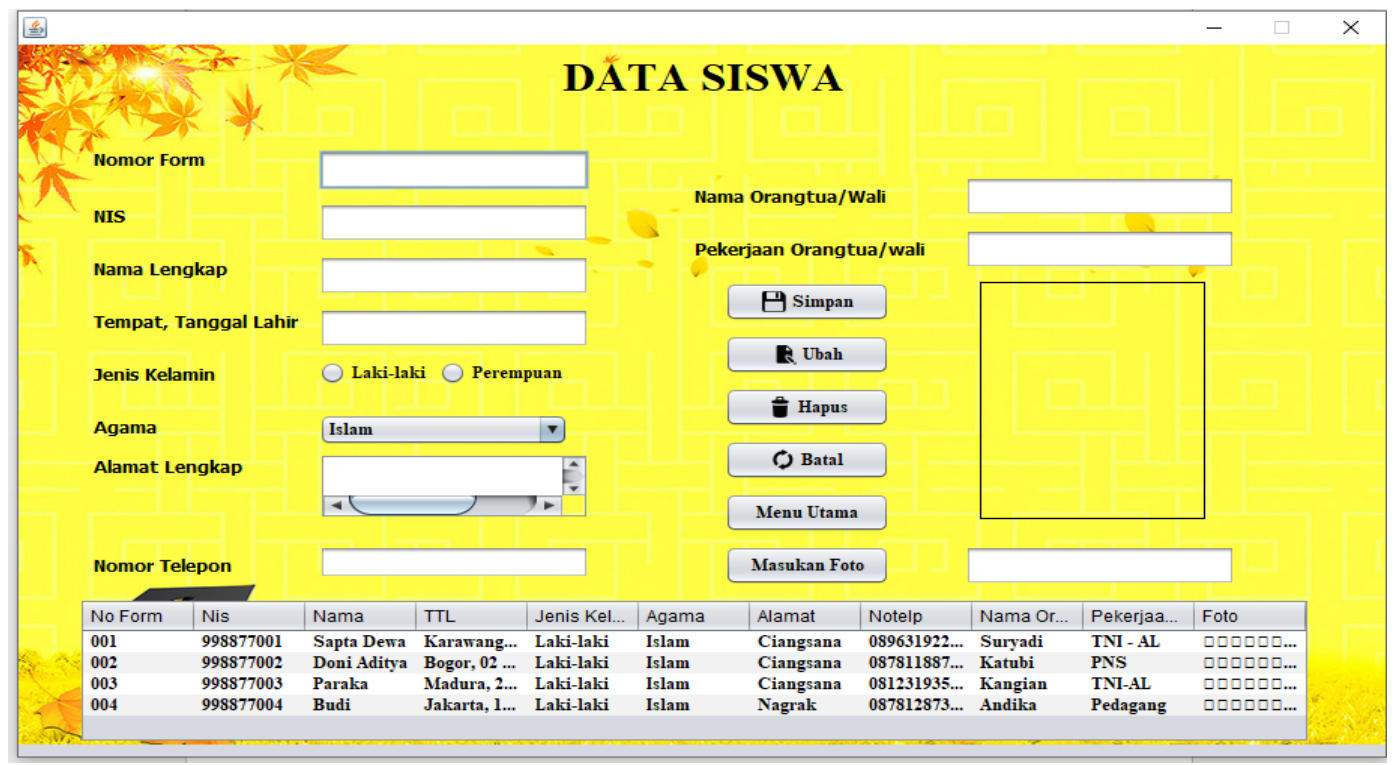

Gambar 8. Tampilan Layar Menu Data Siswa

Tampilan di atas merupakan rancangan tampilan form Data Siswa. Tampilan tersebut diisi ketika siswa mengisi data siswa dan di dalam tampilan form Data Siswa terdapat empat tombol yaitu tombol simpan digunakan untuk menyimpan data siswa, tombol ubah untuk mengubah data siswa, 
tombol hapus untuk menghapus data siswa yang telah terdaftar, tombol batal untuk membatalkan data siswa, tombol menu utama digunakan untuk kembali pada layar menu utama.

7. Tampilan Layar Laporan Pendaftaran

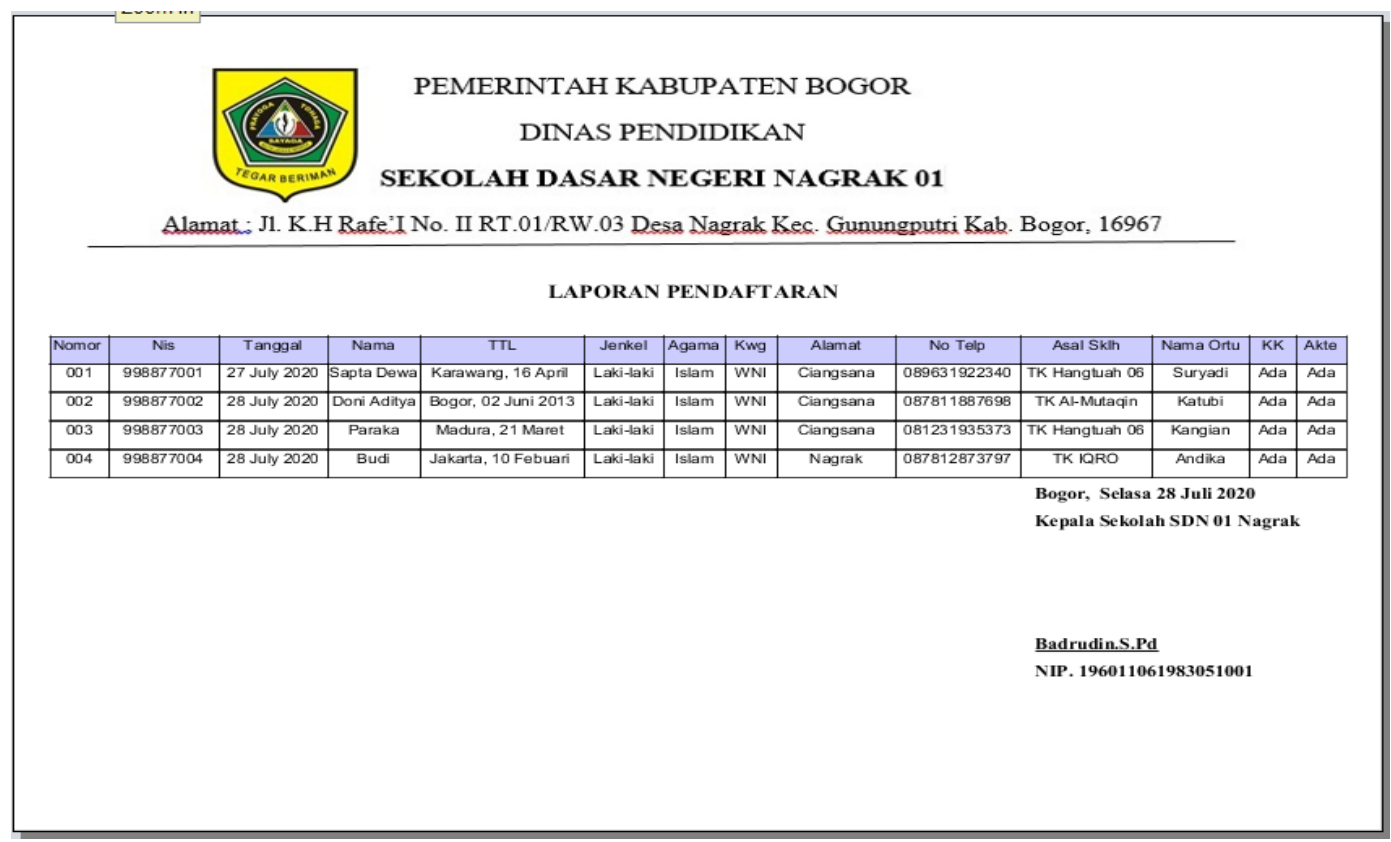

Gambar 9. Tampilan Layar Laporan Pendaftaran

8. Tampilan Layar Laporan Registrasi

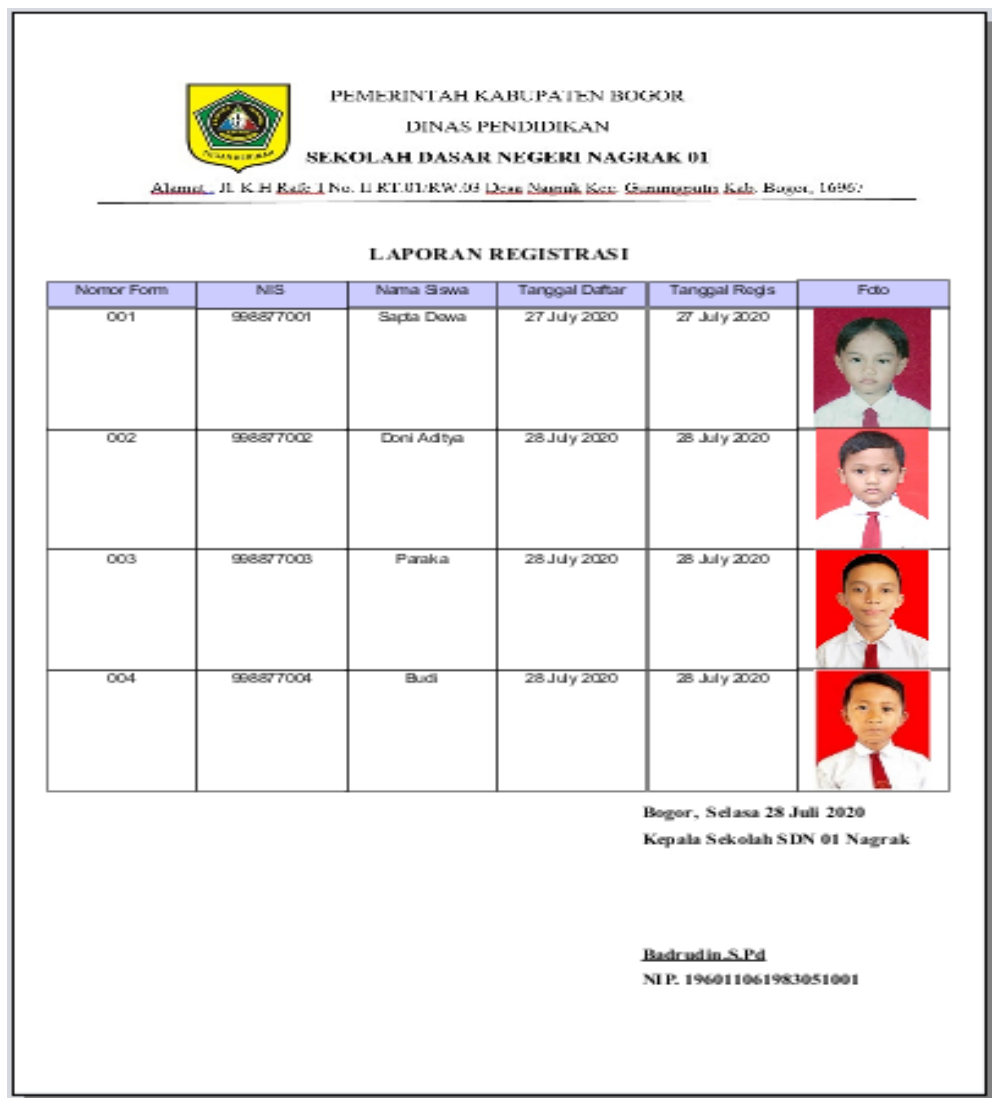

Gambar 10. Tampilan Layar Laporan Registrasi 
9. Tampilan Layar Laporan Data Siswa

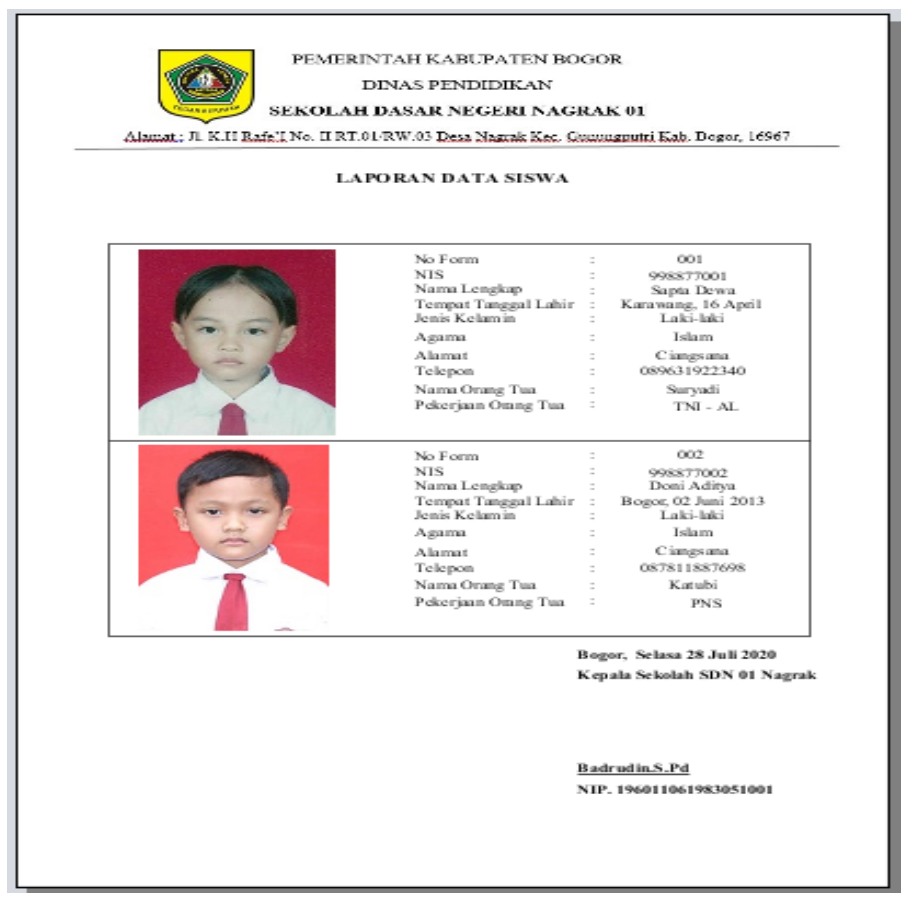

Gambar 11. Tampilan Layar Laporan Data Siswa

\section{SIMPULAN}

Berdasarkan pada tahap-tahap penelitian yang telah dilakukan dalam menganalisis Aplikasi Sistem Penerimaan Peserta Didik Baru Pada SD Negeri Nagrak 01, peneliti menarik kesimpulan sebagai berikut:

1. Dengan sistem informasi yang dibuat mampu memberikan solusi pada permasalahan yang terjadi yakni pengolahan data dan pembuatan laporan.

2. Dengan dibuatnya sistem yang user friendly memudahkan staff untuk mendata penerimaan siswa baru, registrasi siswa, pembayaran dan data siswa.

3. Dengan menggunakan aplikasi sistem ini penyimpanan atau pengarsipan data akan lebih mudah dan rapih.

\section{DAFTAR PUSTAKA}

Muhamad Muslihudin, A. L. (2014). PERANCANGAN SISTEM APLIKASI PENERIMAAN MAHASISWA BARU DI STMIK PRINGSEWU MENGGUNAKAN PHP DAN MYSQL. TAM (Technology Acceptance Model), 3, 32-39.

Najamudin, Wire Bagye, M. A. (2019). APLIKASI PENERIMAAN PESERTA DIDIK BARU BERBASIS WEB PADA SMK NEGERI 2 KURIPAN. Manajemen Informatika \& Sistem Informasi, 2(2), 17-26.

Putri, L. D. (2014). Perancangan Sistem Informasi Penerimaan Siswa Baru Pada Sekolah Menengah Kejuruan Negeri 3 Pacitan. On Networking and Security, 3(4), 1-4.

Rahayu, S., \& Winda Suandi. (2017). Perancangan Sistem Informasi Penerimaan Siswa Baru Berbasis Web di Sekolah Menengah Atas Negeri 14 Garut. Algoritma, 14(2), 255-262.

Ramadhani, N. A. Y. (2011). Pembangunan Sistem Informasi Penerimaan Siswa Baru Di Sekolah Menengah Kejuruan AlIrsyad Tegal. Sentra Penelitian Engineering Dan Edukasi, 3(3), 35-43.

Ramdhan, N. A., \& Wahyudi, D. (2019). Sistem Informasi Penerimaan Peserta Didik Baru ( PPDB ) Berbasis WEB Di SMP Negri 1 Wanasari Brebes. 1(1), 56-65.

Sadikin, I., \& Rusmawan, U. (2017). Sistem pengolahan data penerimaan siswa baru dan pembayaran spp pada smk karya guna 1 bekasi. Methodika, 3(1), 251-257.

Saiful Isnandar, M. T., \& Yogi Arif Virnando. (2014). APLIKASI PENERIMAAN SISWA BARU SMK WIDYA YAHYA VIA WEB MOBILE. TAM (Technology Acceptance Model), 3, 59-66.

Susana Eviani, Syafrika Deni Rizki, M. P. (2016). Sistem Informasi Penerimaan Siswa Baru Berbasis Web Pada Smpn 34 Kabupaten Tebo. Universitas Putra Indonesia YPTK Padang, 1, 1-7.

Umi Kholifah, I. U. W. (2014). Sistem Informasi Pendaftaran Peserta Didik Baru Pada Sekolah Menengah Kejuruan Negeri 1 Sudimoro. On Networking and Security, 3(3), 50-54. 